\title{
REDUCTION OF CARBON DIOXIDE AND NITROGEN OXIDES EMISSIONS FROM COMBUSTION ENGINES OF VEHICLES BY USING BIOMETHANE
}

\author{
Jerzy Merkisz \\ Technical University of Poznan \\ Institute of Internal Combustion Engines and Transport \\ Piotrowo Street 3, 60-965 Poznan \\ tel.: +48616652207 \\ e-mail:jerzy.merkisz@put.poznan.pl \\ Wojciech Gis \\ Motor Transport Institute \\ Jagiellonska Street 80, 03-301 Warsaw \\ tel.: +48602247823 \\ e-mail:wojciech.gis@its.waw.pl
}

\begin{abstract}
This paper discusses generally the possibility of reduction carbon dioxide and nitrogen oxides emissions from internal combustion engines of vehicles by using biomethane. The road transport in Europe almost fully depends on fossil fuels. Diversification of the road transport fuels will be a key attribute for road transport in the coming years. Purified biogas is one of alternative renewable fuels. Actually, in Poland biogas is used for generating electricity and heat. In some countries (for example in Sweden), upgraded biogas to natural gas quality (biomethane) is used as a vehicle fuel too. In this paper estimated biogas production potential in Baltic See Region countries: Poland and Sweden. It was one of the purposes of European Project Baltic Biogas Bus, and it is taken into account in European Project More Baltic Biogas Bus realized presently. Comparative studies of exhaust emissions of carbon dioxide and nitrogen oxides from city buses powered by diesel and CNG engine were carried out. The study was conducted under real traffic conditions in southern Polish city Rzeszow. Due to the lack in-service city buses with emission level Euro $V$ in Rzeszow, comparative studies of this type of city buses powered by diesel and CNG engine was conducted in SORT I test. Determined mean values of road emissions of carbon dioxide and nitrogen oxides in $\mathrm{g} / \mathrm{km}$ for the city buses operated in Rzeszow. Estimated value of the total road emissions in the case that would be replaced half the fleet of city buses (40 CNG buses and about 35\% of the diesel engine powered buses, meet Euro III emission standard) by the $C N G$-powered (biomethane) city buses, complying with Euro V (EEV) emission standard.
\end{abstract}

Keywords: vehicles, combustion engines, pollutants, biomethane

\section{Introduction}

Feedstock for biogas production is mostly derived from agricultural, municipal and industry wastes. Biogas can be produced by the anaerobic digestion (AD) of a range of organic wastes, with the key wastes being [1]:

- sewage sludge,

- wet manure slurries from intensive styles of agriculture,

- dry manures from animal beddings, known as farm yard manure,

- waste from food processing,

- food and organic waste from restaurants and other commercial operations,

- household kitchen and garden wastes. 
Biogas can also be produced by thermal gasification, which is a process where the biomass or organic waste is heated under limited amounts of oxygen. The heat decomposes the organic material and gases as carbon dioxide, hydrogen, stream, carbon monoxide and methane are produced. Biogas produced this way is called SNG, Synthetic Natural Gas [1].

Biogas upgrading technologies are enabled for cleaning and removing: water, hydrogen sulfide, oxygen, nitrogen, ammonia, siloxanes, particles; increasing energy content by removing carbon dioxide; conditioning for distribution e.g.: odorization, compression; treatment of off-gas [10].

Biogas upgrading technologies are presently following water scrubbing, PSA (Pressure Swing Adsorption), chemical absorption, membrane and cryogenic [10]. In result of these processes, emerge biomethane. Biomethane can be used by SI engines of vehicles directly (as CBG or LBG) or can be injected as upgraded biogas into grid. Tab. 1 presents Swedish Standard for purified biogas as a fuel for SI engines [10].

Tab. 1. Swedish Standard for biogas as fuel for SI engines [10]

\begin{tabular}{|l|} 
Particles $<1 \mu \mathrm{m}$ \\
Methane $97 \pm 2 \%$ \\
Water $<32 \mathrm{mg} / \mathrm{Nm}^{3}$ \\
$\mathrm{CO}_{2}, \mathrm{O}_{2}, \mathrm{~N}_{2}<5 \%$ \\
Oxygen $<1 \mathrm{vol} \%$ \\
Sulphur $<23 \mathrm{mg} / \mathrm{Nm}^{3}$ \\
$\mathrm{~N}\left(\right.$ except for $\mathrm{N}_{2}$ ) expressed as $\mathrm{NH}_{3}<20 \mathrm{mg} / \mathrm{Nm}^{3}$ \\
Odorised \\
Compressed to 200 bar \\
For grid injection: Addition of propane (around 7-9 vol\%) \\
\hline
\end{tabular}

Why consider purified biogas as a transport fuel? There are four main arguments supporting the use of purified biogas as a transport fuel [2]:

- biogas is a renewable fuel, derived from the anaerobic digestion of organic wastes or biomass crops, and as such it can contribute to reducing carbon dioxide emissions from transport and tackling climate change,

- as a renewable fuel, biogas helps move us away from our dependence on fossil fuels, especially oil, and so it is important with regard to security of energy supply,

- as a product of an organic waste treatment process the use of biogas also helps in the management of waste, so it is both a waste treatment and energy production process,

- the exhaust emissions from purified biogas-fuelled vehicles are relatively low in particulates and nitrogen oxides and so can contribute to improving local air quality.

There are a number of policies, and there are legislative instruments that support these reasons and suggest purified biogas as an option to pursue, and include:

- climate change and carbon reduction targets,

- EU Biofuels Directive - with targets for biofuels use in transport,

- EU Landfill Directive - driving a reduction in organic waste going to landfills,

- EU animal by-products directive - restricting the landfilling of animal waste or use in animal feeds,

- local air quality management - with the key issues being particulate and NOx emissions from transport means.

What are the barriers and possible incentives for the application of purified biogas as a vehicle fuel? The data and analysis suggests there is a significant environmental benefit from the development of biogas as a vehicle fuel, however, there are clearly a number of barriers to overcome 
given the current limited development of both $\mathrm{AD}$ (anaerobic digestion) and gas vehicles. The key barriers would appear to be [2]:

- there is limited experience with centralized AD systems treating a range of waste materials, and so the risks for investment are seen as high,

- currently the economics and practicality of using biogas for electricity production are more favourable than using it as a vehicle fuel,

- there is also limited understanding of using biogas as a vehicle fuel in the biogas production industries,

- the current (for instance PL or UK) gas vehicle market suffers from poor availability of both refuelling infrastructure and vehicles, and so provides a limited market to potential fuel suppliers,

- the additional capital costs of gas vehicles outweigh the potential fuel costs savings in most cases, and so it is viewed as an uneconomical fuel by vehicle operators,

- the lack of experience of gas vehicles and the limited fleet sizes for instance in PL or in the UK have resulted in concerns about reliability of gas vehicles.

In Sweden, strongly built on the use of purified biogas as vehicle fuel. It should be assumed that also in Poland this type of initiative would take place. To support this European project More Baltic Biogas Bus is a continuation of the European Project Baltic Biogas Bus. In these projects are involved representatives of the countries of the Baltic Sea Region, including the authors of this paper.

\section{Production and production potential of biogas in Sweden and Poland}

The Fig. 1 shows total biogas potential in Baltic Sea Region (Baltic Biogas Bus European project) countries.

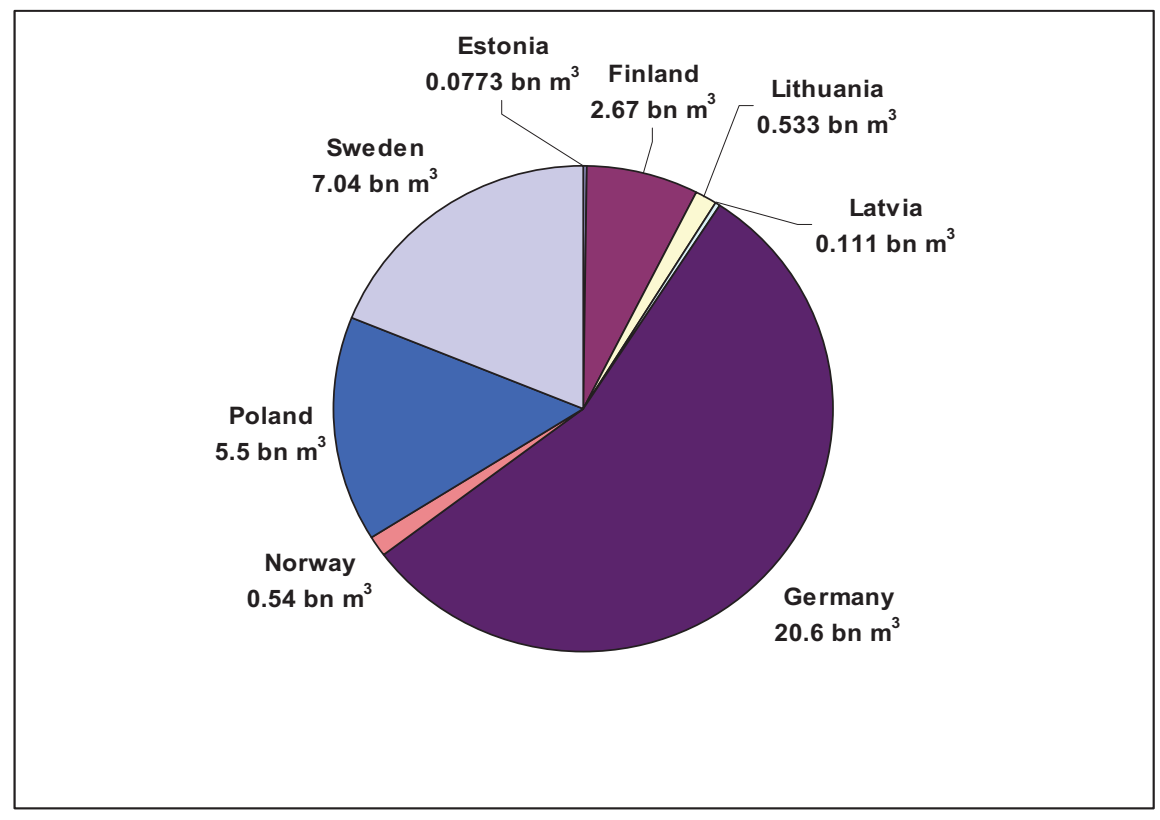

Fig. 1. Total biogas potential in BBB countries (bn $\left.\mathrm{m}^{3}\right)$ [1]

Table 2 shows the number of biogas plants and biogas upgrading plants (biomethane plants) in the Baltic Biogas Bus project countries as well as in Denmark.

It appears from the Fig. 1 and Tab. 2 that in countries involved in the Baltic Biogas Bus European Project and More Baltic Biogas Bus European Project there is a significant potential for biogas production and the use of this potential is high only in Germany, while in Latvia and in Sweden significant. The relatively important utilisation of the biogas production potential takes place also in Denmark. 
Tab. 2. Number of biogas plants and biogas upgrading plants in the Baltic Biogas Bus European Project countries [1]

\begin{tabular}{|c|c|c|}
\hline Country & Number of biogas plants & Number of biomethane plants \\
\hline Germany & 5905 (2010); $7470(2012)$ & $60(2011) ; 80(2012)$ \\
\hline Sweden & $229(2010)$ & $\begin{array}{c}48 \\
\text { (39 biomethane injection) }\end{array}$ \\
\hline Poland & $144^{1 /} ; 178^{2 /}$ & - \\
\hline Denmark & 82 & - \\
\hline Finland & $71(2010)$ & $2(+2$ on experimental level) \\
\hline Norway & 35 & 3 \\
\hline Latvia & 7 (2009); 10 (2010); 32 (2013 and beyond) & - \\
\hline Lithuania & $7(2009) ; 14-16(2012-2013)$ & - \\
\hline Estonia & $\begin{array}{l}3 \text { (2009); ( } 4-6 \text { new biogas plants will be opened during } \\
\text { the II half of } 2012 \text { or in the beginning of } 2013)^{3 /}\end{array}$ & $\begin{array}{l}1 \text { biogas upgrading plant planned to } \\
\text { open in } 2012-2013 \text { in Tartu }\end{array}$ \\
\hline
\end{tabular}

In Poland, for example, there is significant potential for biogas production. It is significant even in the case of using only $20-25 \%$ of this potential for public transport buses, given that in Poland in 2009 (in the companies and transport companies employing more than 9 people), the state of the fleets of buses in urban transport amounted to 11755 vehicles and for the operation of 100 buses per year, the biogas production should shape up at about 6 million $\mathrm{m}^{3}$. Unfortunately, in Poland not purified biogas to natural gas quality. In Sweden, already a significant number of buses are powered by biogas (biomethane). For example, in Stockholm in 2011, there were 230 buses powered by biomethane used. In the other countries involved in the project Baltic Biogas Bus, the potential to produce biogas (biomethane) to power city buses is also beneficial.

Production and production potential of biogas in Sweden is illustrated in Tab. 3 [1].

Tab. 3. Production and production potential of biogas in Sweden [1]

\begin{tabular}{|c|c|c|}
\hline \multirow{2}{*}{ Country } & $\begin{array}{c}\text { Average total production potential } \\
(2010-2011)\end{array}$ & Total production (2009) \\
\cline { 2 - 3 } & PJ & PJ \\
\hline Sweden & $50.4-61.2(214.8)$ & 4.57 \\
\hline
\end{tabular}

So, the production of biogas is used in $7.5-9.1 \%(2.1 \%)$ (average value: $8.3 \%$ ).

According to the Energy Regulatory Office, on the beginning of the 2012 there were 178 biogas plants in Poland, including [4]:

- 21 agricultural biogas plants,

- 67 biogas plants that produce biogas from sewage treatment plants,

- 89 biogas plants that produce biogas from landfills,

- 1 biogas plant that produce biogas from mixed substrate.

Poland received $251.8 \mathrm{GWh}$ of electricity and $925 \mathrm{TJ}$ of heat from biogas produced in 2008 . However, at the beginning of 2010 there were 124 facilities for the production of biogas with total capacity of $70.8 \mathrm{MW}[3,4,6,9,11]$.

Production and production potential of biogas in Poland is illustrated in Tab. 4 [1].

Tab. 4. Production and production potential of biogas in Poland [1]

\begin{tabular}{|c|c|c|}
\hline \multirow{2}{*}{ Country } & Average total production potential (2010-2011) & Total production (2009) \\
\cline { 2 - 3 } & PJ & PJ \\
\hline Poland & $52.3-115(410.4)$ & 4.10 \\
\hline
\end{tabular}

So, the production of biogas is used in 3.6-7.8\% (average value 5.7\%); (1\%). 


\section{Research cars in real traffic conditions}

Determination for passenger cars emissivity in road conditions and to compare it with the values obtained on the chassis dynamometer during test approval allowed for the determination of the emission correction coefficient, which is used to answer the question whether the emission in traffic conditions is comparable with the emission achieved during the type approval test (this correction coefficient is expressed fold increase (or decrease) emissions in real traffic conditions in relation to the type approval test). At the same time, it is a verification of the conditions driving during type approval test (developed many years ago) and the real traffic conditions of vehicles [5].

The analysis of the data presented in Fig. 2 shows that the emission values obtained in real conditions in the case of passenger cars are exceeded for vehicles with diesel engines, while for SI engines did not give a clear answer when compared to the value adopted with the relevant standard. There is a variability in the measurements values for different routes [5].

\section{Cars - gasoline engines}

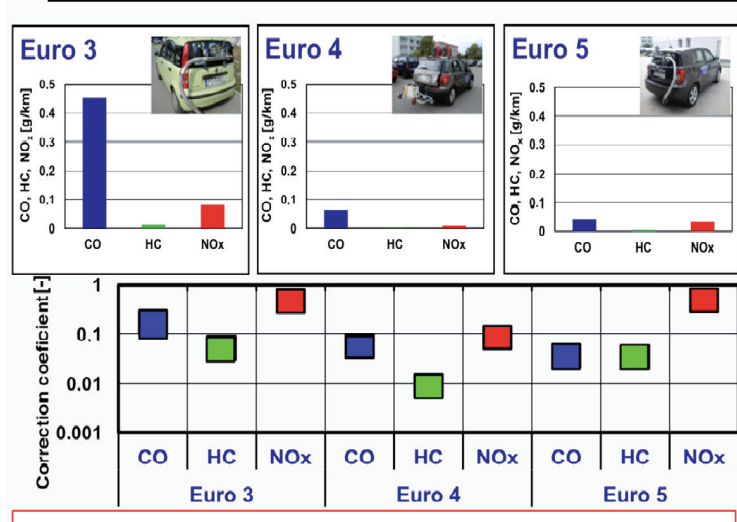

Emission do not exceed the limits of the standard
Cars - Diesel engines

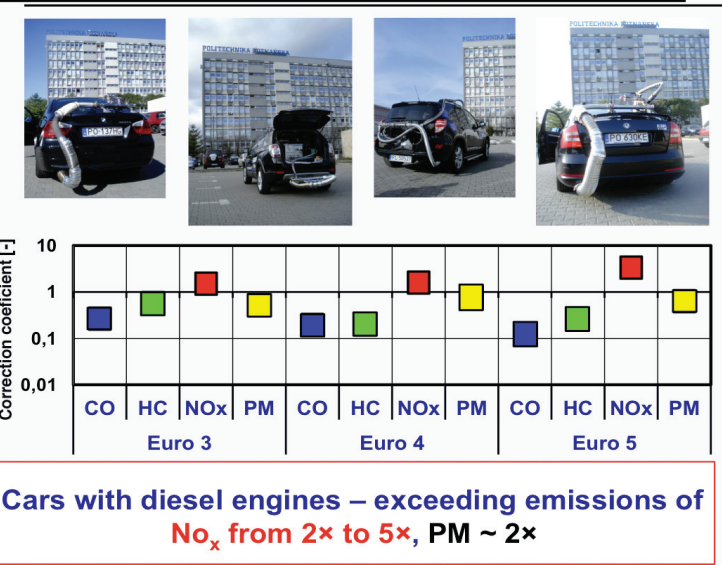

Fig. 2. Values of emission correction coefficients for vehicles powered by engines SI and Diesel engines [5]

For alternative fuel vehicles during road tests, observed increased emissions of pollutants when powered by LPG vehicles were adapted to this power outside the factory [12].

Obtained emission correction coefficients for powered by petrol and CNG vehicle are characterised emissivity of vehicle in traffic conditions with regard to emission standards, which the vehicle should meet.

In connection with the adoption of $\mathrm{CNG}$ fuel, emission correction coefficients of vehicle powered by gasoline are much worse: the value of the emission of carbon monoxide for petrol supply $\left(\mathrm{k}_{\mathrm{CO}}=3.9\right)$ shows a significant (fourfold) overshoot the Euro 4 standards for this vehicle (Fig. 3). Other values of emission correction coefficient (for hydrocarbons and nitrogen oxides) do not exceed the values set in the exhaust emissions legislation (Fig. 3), although the observed slightly increased emissions of $\mathrm{NO}_{\mathrm{x}}$ by $\mathrm{CNG}$ vehicles for this adapted (Fig. 4) [12].

\section{Research of trucks and buses in real traffic condition}

Research the influence of loading cargo vehicles for the emission of toxic compounds show an almost twofold increase of emissions, including $\mathrm{NO}_{\mathrm{x}}$ for vehicles so loaded (Fig. 5) [5].

The emissivity of city buses due to the specific conditions of their use can be assessed as a rule, during tests on engine test bench, but also on the chassis dynamometer of heavy vehicles. 


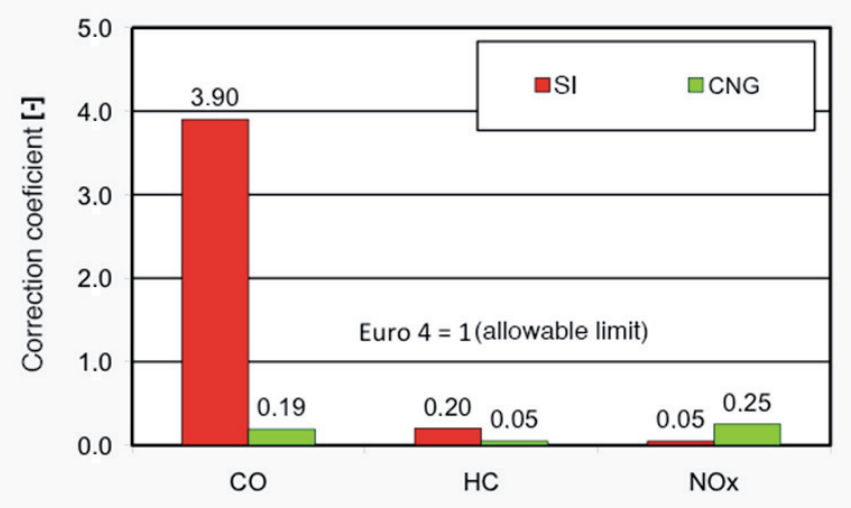

Fig. 3. Comparison of emission vehicles powered by gasoline and CNG (SI engines) [12]

\section{Comparison of petrol and CNG}

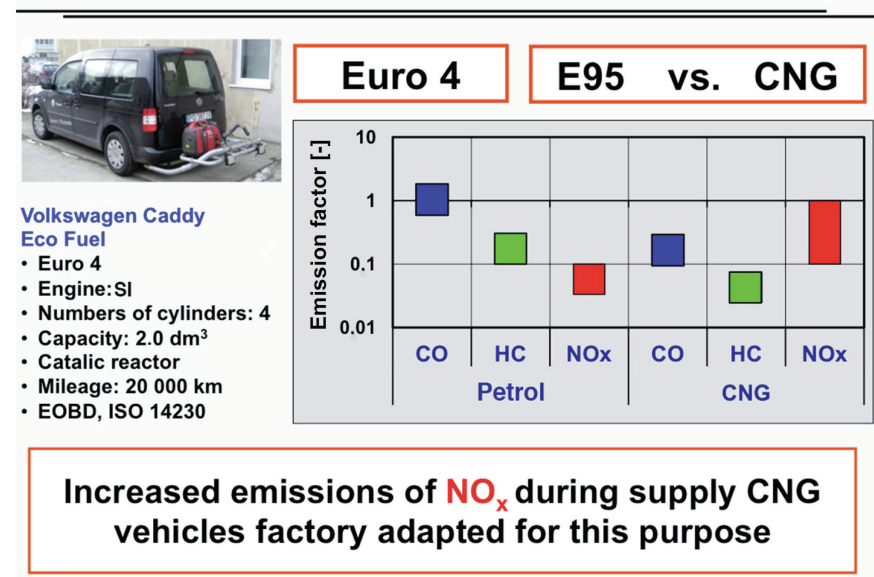

Fig. 4. Values of emission factors for vehicles powered by CNG engines [5]

Trucks

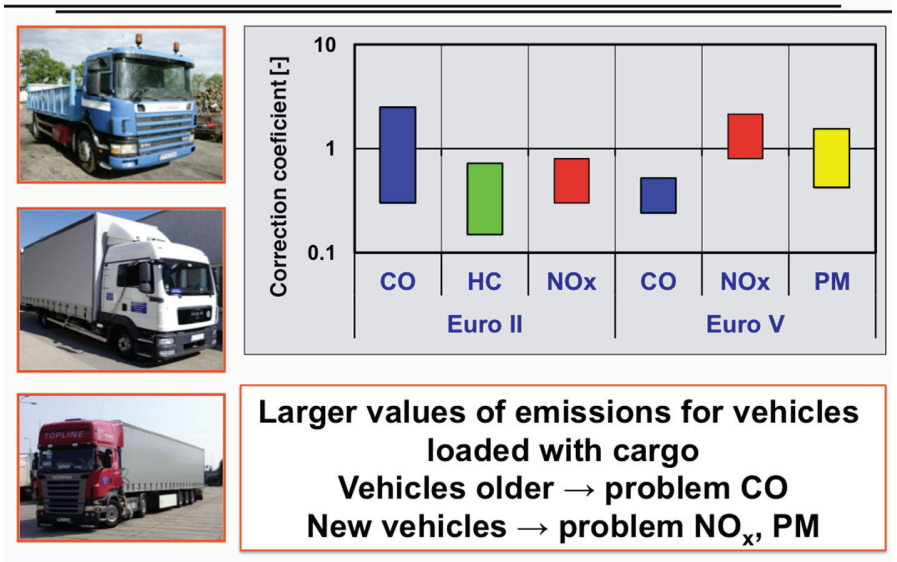

Fig. 5. The values of emission correction coefficients for trucks [5]

Purified biogas (biomethane) is similar to natural gas but renewable.

Results of research introduce in indicate that [7]:

- currently EEV certified methane buses clearly outperform EEV certified diesel vehicles for $\mathrm{NO}_{\mathrm{x}}$ as well as PM,

- methane vehicles provide true EEV performance over time, 
- all methane fuelled vehicles deliver very low PM emissions,

- stoichiometric vehicles deliver lower $\mathrm{NO}_{\mathrm{x}}$ and lower fuel consumption,

- clear benefit for methane also for unregulated emissions (PM numbers, aldehydes, PAH, direct $\mathrm{NO}_{2}$ emissions etc.),

- main drawback of spark-ignited methane compared to diesel is higher energy consumption.

Table 5 presents results of above research of exhaust emissions from EEV buses (diesel and $\mathrm{CNG}$ ) [7]. It is necessary to remember that biomethane is renewable fuel and therefore $\mathrm{CO}_{2}$ emission from well to wheel is much smaller in the case of vehicles (buses) powered by biomethane compared to diesel-powered (Fig. 6) [8].

Tab. 5. Exhaust emission from city buses (Braunschweig cycle carried on a chassis dynamometer) [8]

\begin{tabular}{|l|c|c|c|c|c|c|c|}
\hline \multicolumn{1}{|c|}{ City bus-cycle } & $\begin{array}{c}\mathrm{CO} \\
\mathrm{g} / \mathrm{km}\end{array}$ & $\mathrm{HC} \mathrm{g} / \mathrm{km}$ & $\begin{array}{c}\mathrm{CH}_{4}{ }^{*} \\
\mathrm{~g} / \mathrm{km}\end{array}$ & $\begin{array}{c}\mathrm{NO}_{\mathrm{x}} \\
\mathrm{g} / \mathrm{km}\end{array}$ & $\mathrm{PMg} / \mathrm{km}$ & $\begin{array}{c}\mathrm{CO}_{2} \\
\mathrm{~g} / \mathrm{km}\end{array}$ & $\begin{array}{c}\mathrm{CO}_{2} \mathrm{eqv} \\
\mathrm{g} / \mathrm{km}\end{array}$ \\
\hline Diesel Euro III & 0.80 & 0.14 & 0.00 & 8.64 & 0.195 & 1189 & 1189 \\
\hline Diesel Euro IV & 2.84 & 0.10 & 0.00 & 8.35 & 0.112 & 1194 & 1194 \\
\hline Diesel Euro V & 2.84 & 0.10 & 0.00 & 8.35 & 0.087 & 1194 & 1194 \\
\hline Diesel EEV & 1.12 & 0.02 & 0.00 & 5.87 & 0.062 & 1116 & 1116 \\
\hline $\mathrm{CNG}^{*}$ Euro III & 0.14 & 1.67 & 1.14 & 9.36 & 0.011 & 1257 & 1295 \\
\hline $\mathrm{CNG} \mathrm{EEV}^{2.27}$ & 1.04 & 0.87 & 3.18 & 0.007 & 1275 & 1294 \\
\hline * for diesel $\mathrm{CH}_{4}=0 ; * *$ Euro V emission factors are estimated by Euro IV results \\
\hline
\end{tabular}

WTW GHG - RED

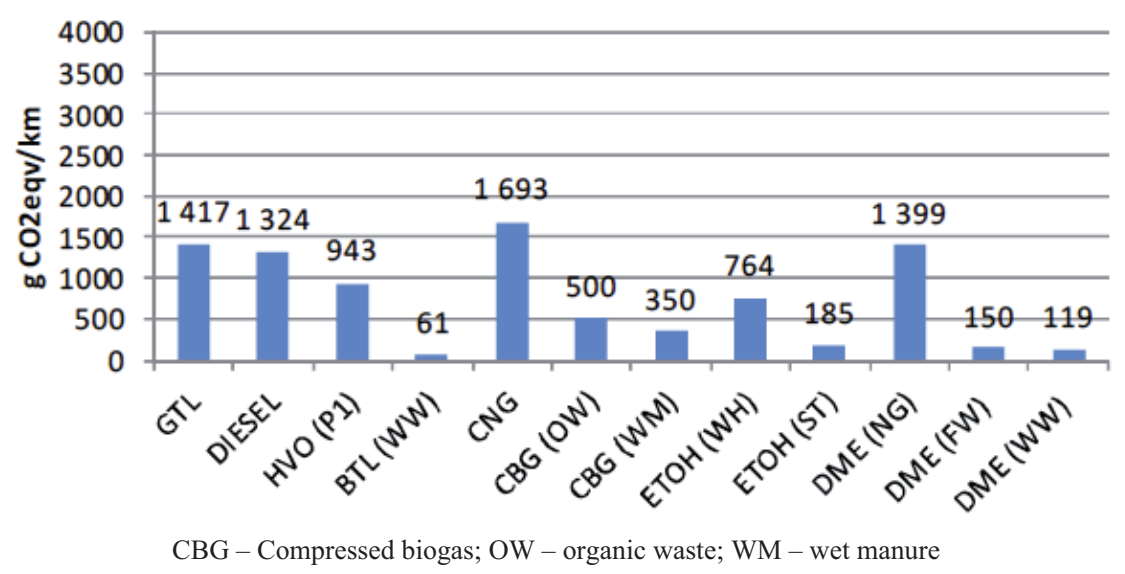

Fig. 6. WTW GHG road emissions in case diesel-powered buses (SCRT) and alternative fuels by methods RED in Braunschweig cycle carried on a chassis dynamometer [8]

Our study of exhaust emission was conducted for city buses in Rzeszow (southern Polish city) in the real traffic conditions. Operated in Rzeszow buses (MPK Rzeszow) are characterized by exhaust emission levels not higher than Euro III. These are mainly buses powered by compression ignition (CI) engines, in the number of 148 buses, and powered by spar ignition (including diesel buses retrofitted to CNG buses (lean mixture)).

Posed the question how to change the total exhaust emissions of city buses operated in MPK Rzeszow, if in the process of replacement buses for the new to 2020, about $50 \%$ of buses will be replace to buses powered by $\mathrm{CNG}$ (biomethane) engines. It is assumed that the replacement of buses, will be for new design to supply CNG (biomethane) by the manufacturer. They will by comply with the emission standards Euro IV or Euro V. 
Due to the lack of buses that meet such standards in MPK Rzeszow comparative study was conducted in SORT test using the buses meet Euro V-EEV. It was made comparison of exhaust emission of buses powered by diesel and spark-ignition engine (powered by CNG).

For the evaluation of the mutual correlation of each pollutant emissions from buses powered diesel and CNG, at random were selected MPK Rzeszow bus route occurring in Rzeszow, which was conducted on assessment of pollutant emissions. Research was made on a circular route No. 0 passing direct through centre of the city and on route No. 30, which is one of the longest routes of the circulation of buses in Rzeszow. The total number of MPK Rzeszow bus route is 42 .

The result buses pollutants emissions evaluated on other route show that above selected bus routes are representative of population of MPK Rzeszow bus route. Additionally in Bednary (near Poznan) SORT 1 driving tests were conducted on two buses, diesel and CNG powered engine.

The road emission of bus tested on MPK bus route No. 30 is illustrated in Fig. 7, however the road emission values of tested buses in a SORT 1 test is illustrated in Fig. 8.

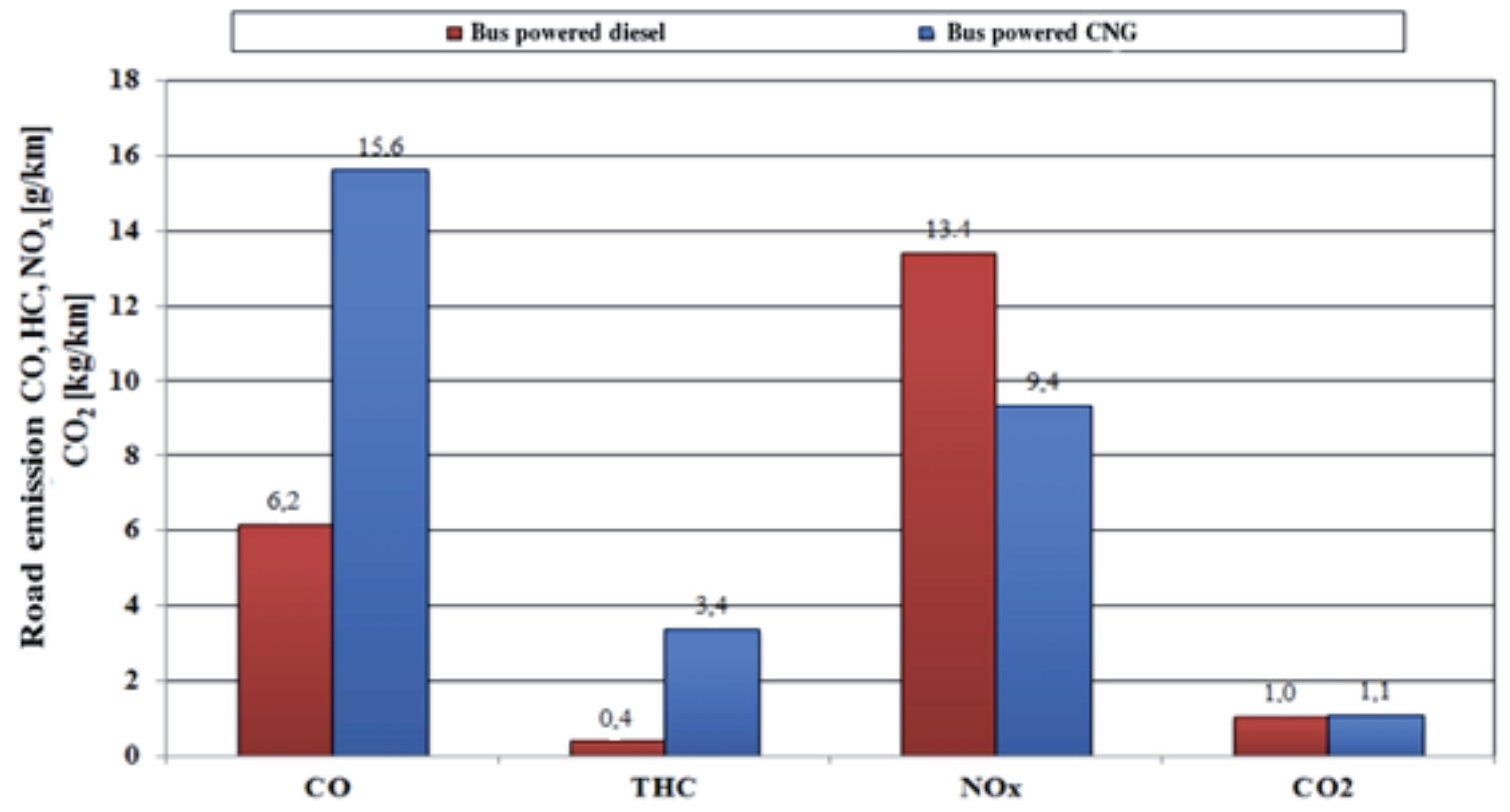

Fig. 7. The road emission of bus tested on MPK bus route No. 30

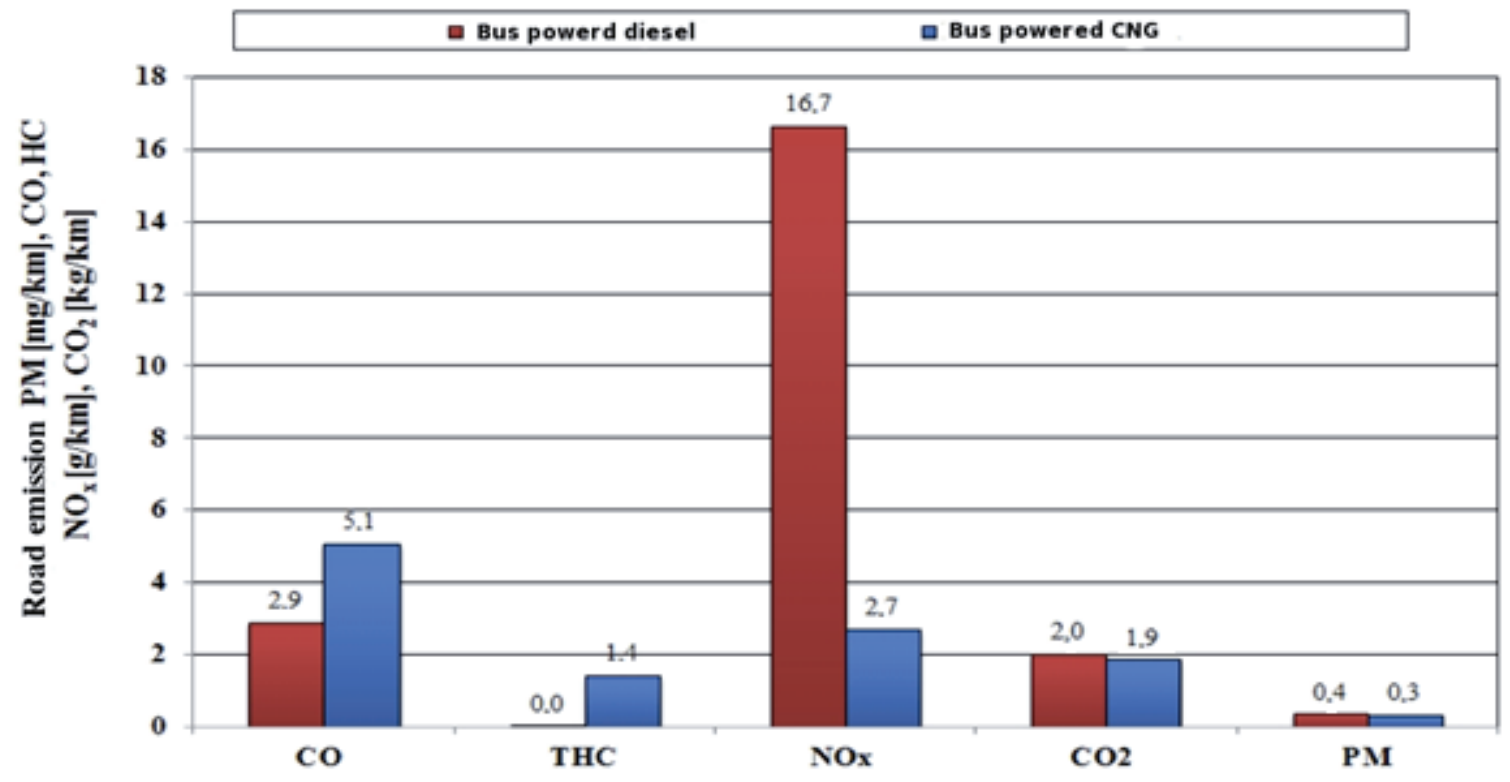

Fig 8. The road emission values of tested buses in a SORT 1 test 
The highest emissions of $\mathrm{CO}$ and $\mathrm{THC}$ reached bus powered $\mathrm{CNG}$ engine (bus route No. 30 ). This was caused by work of engine on almost stoichiometric mixture due to the used in the bus three-function catalytic converter.

On the MPK bus route No. 30, bus powered diesel engine has reached the highest average value of $\mathrm{NO}_{\mathrm{x}}$ road emissions and lowest average value of $\mathrm{CO}_{2}$ road emissions. $\mathrm{CNG}$ engine powered bus has reached the highest average value of road emissions of THC, which for a bus diesel engine powered was approximately $850 \%$. This was due to the combustion reaction of natural gas, whose products next to the $\mathrm{CO}_{2}, \mathrm{NMHC}$ and $\mathrm{CH}_{4}$.

\section{Conclusion}

According to the knowledge and experience of the participants of recent conferences: $35^{\text {th }}$ International Vienna Motor Symposium, $4^{\text {th }}$ Bosmal International Exhaust Emissions Symposium, $35^{\text {th }}$ FISITA World Automotive Congress and Seminar of Association for Emissions Control by Catalyst, Conventional powertrain will continue to play a major role in the next decades. Therefore, in the nearest future, combustion engines will continue their domination, only the type of fuel will change.

Therefore, any substitution of conventional fuels by alternative is right and targeted.

The research has shown that NOx emission from city buses fuelled with diesel oil is higher that from city buses fuelled CNG. The reason for this is no aftertreatment for conventional diesel engines and the application of Three Way catalyst for CNG fuelled engines. Further reduction of exhaust emission from $\mathrm{CNG}$ fuelled engines can be obtained through optimization of the operation of TWOC.

The results of research indicate the possibilities that offered by the use of $\mathrm{CNG}$ (biomethane) with respect to the reduction of $\mathrm{NO}_{\mathrm{x}}$ in the case of vehicles with different levels of emission limits these exhaust pollutants. Biomethane is a renewable fuel and $\mathrm{CO}_{2}$ emissions using this fuel in the so-called life cycle, from the well to the wheels is very small, much smaller than in the case of diesel or CNG to supply of vehicle engines.

\section{References}

[1] Biernat, K., Dziołak, P., Gis, W., Żółtowski, A., The study on wider range of biogas production options and experiences, Motor Transport Institute, Baltic Biogas Bus European Project, Warsaw 2013.

[2] Biogas as a road transport fuel, NSCA, June 2006.

[3] Environmental Protection 2008, Central Statistics Office, Information and Statistical Studies, Warsaw 2008.

[4] Map of renewable energy sources, developed by studies the Energy Regulatory Office, http://www.ure.gov.pl/uremapoze/mapa.html.

[5] Merkisz, J., Emisja spalin środków transportu w rzeczywistych warunkach ruchu, Radom 2014.

[6] Ministry of Agriculture and Rural Development. Assumptions biogas development program. Program Innovative Energy, Agriculture Energy, Warsaw 2009.

[7] Nylund, Nils-Olof, Environmental benefits with biogas buses, Nordic Biogas Conference Oslo 2010.

[8] Nylund, N.-O., Koponen, K., Fuel and Technology Alternatives for Buses. Overall Energy Efficiency and Emission Performance. VTT Technology 46, Espoo, Finland 2012.

[9] Obtaining biogas from municipal waste, Editors: agroenergetyka.pl http://agroenergetyka.pl/?a=article\&idd $=149$.

[10] Petersson, A., Overview of upgrading technologies, Nordic Biogas Conference, 2010. 
[11] Production of biogas from waste water treatment plants, Editors: aeroenergetyka.pl http://agroenergetyka.pl/?a=article\&id=529.

[12] Merkisz, J., Pielecha, J., Radzimiński, S., New Trends in Emission Control in the European Union, Series: Springer Tracts on Transportation and Traffic, STTT 4, Vol. 4. 2014, XII, p. 165, 2014. 